\author{
Review Article
}

\title{
THE ART AND SCIENCE OF CONSULTATIONS IN BOVINE MEDICINE: USE OF MODIFIED CALGARY - CAMBRIDGE GUIDES
}

\author{
Kiro R. Petrovski, Michelle Mc Arthur \\ School of Animal and Veterinary Sciences, the University of Adelaide, SA, Australia
}

Received 20 March 2015; Received in revised form 8 May 2015; Accepted 12 May 2015

\begin{abstract}
This article describes few steps of the application of the modified Calgary-Cambridge Guides (CCG) to consultations in bovine medicine. A review of pertinent clinical communication skills literature in human medicine was integrated with the burgeoning research within veterinary medicine. In particular, there are more recent studies examining companion animal veterinarian's communication skills and outcomes which can be extrapolated to practitioners. This was integrated into a teaching example of a reproductive case consultation. The first article deals with the 1) Preparation, 2) Initiating the Session and 3) Gathering Information sections. The aim of the modified CCG is to provide a set of skills to facilitate a relationship-centred approach to consultations in bovine medicine, both at the individual animal and population level. They were initially developed for human medicine and expanded recently for use in veterinary medicine. The CCG enable the practitioner to facilitate interacting with that particular client at the time of the consultation. It is likely that the majority of practitioners do use many of the skills recommended by the modified CCG. These skills are often gained through experience. However, they may not use the skills intentionally and with purpose for a specific communication goal or outcome. Practitioners can improve their communication skills using the set of skills as recommended by the modified CCG. They allow the practitioner to gain insight into the client's understanding of the problem, including underlying aetiology, epidemiology and pathophysiology. The guides also provide opportunity to understand client's expectations regarding the outcome, motivation and willingness to change and adherence.
\end{abstract}

Key words: modified Calgary-Cambridge guides, practitioner, client, consultation

\section{INTRODUCTION}

Successful bovine consultation relies on good communication skills and a healthy clientpractitioner relationship. The objective is to create conducive conditions aiming to establish an effective relationship. Key facets of an effective relationship include appreciating the other's perspective which inherently involves taking time to understand the other party's story as well as shared decision making and ultimately a collaborative approach. Specific effective and efficient communication skills to help achieve the above include both verbal and nonverbal components. Multiple benefits may be realised from collaborative relationship-centred communication

Corresponding author: Dr. Kiro R. Petrovski, $\mathrm{PhD}$

E-mail address: kiro.petrovski@adelaide.edu.au

Present address: The University of Adelaide

School of Animal and Veterinary Sciences

JS Davies building G13, Roseworthy Campus, Roseworthy, Australia

Phone: +61 883131492 / Fax : +61 883137956

Copyright: (C) 2015 Petrovski K. This is an open-access article published under the terms of the Creative Commons Attribution License which permits unrestricted use, distribution, and reproduction in any medium, provided the original author and source are credited.

Competing Interests: The authors have declared that no competing

interests exist.

Available Online First: 18 May 2015

http://dx.doi.org/10.14432/j.macvetrev.2015.05.044 styles and inherent skills. These benefits include anticipated increased adherence to recommendations (1), and improved client and veterinarian satisfaction $(2,3)$. However, ineffective communication, as determined from the client's perspective, is one of the leading causes of complaints at the Veterinary Surgeons Board of South Australia. While clients are typically more informed in recent times, mostly due to freely available data on the internet, the practitioner works with a professional, whose job it is to know intimately the health and husbandry of his/her stock. As such, the practitioner -clientpatient relationship, like those in other production animal settings, is typically a unique and specialised communication domain.

Practitioners are required on farms for individual patient and/or herd problem consultations and both require in effect a case management approach. Despite the recent changes in the cattle industry, particularly dairy, including larger herd size, less contact of labour per patient and decreased importance of treatment of individual animals, case management is still required. This is true for smaller farms, but also for large dairy enterprise-type farms, provided the intervention is economically 
justified and/or addresses animal welfare issues. Given the cost associated with economically justified consultation, involving the judicious use of ancillary techniques and laboratory testing, it is even more important that a complete and thorough history is gathered with the client. A very early empirical study suggested that significant reduction in diagnostic tests in human medicine and thereby costs could be achieved with thorough information gathering and clinical examination (4). Additionally, the practitioner will need to develop proficiency in clinical examination as well as the appropriate choice of diagnostic techniques. To achieve a successful outcome, the practitioner must be inquisitive, critically reflective, and observant. This will prevent overlooking any abnormality in either the animal/s, or the environment.

In dealing with clinical cases practitioners usually use the tailored traditional case management skills that involve the following steps:

\section{a. Collection of data or clinical findings}

i. Client concern

ii. Gathering history

iii.Clinical examination

iv. Ancillary examination techniques

v. Collection and assaying appropriate samples

\section{b. Analysis of data or evaluation of clinical} findings

i. Generation of a list of problems

ii. Generation of a list of differential diagnoses (for each problem; diagnostic hypotheses)

iii. Rule in or out differential diagnosis

iv.Establishing final diagnosis

\section{c. Development of a management plan}

i. Determining a prognosis

ii. Treatment plan

iii.Establishing a programme to prevent recurrent and new cases

The Calgary-Cambridge Guides (5) are a widely accepted model for teaching communication skills in human (6) and veterinary medicine (7). The Calgary Cambridge Guides integrate the content of a clinical case with effective communication skills (5). The modified Calgary Cambridge Guides (MCCG) were developed by Radford et al. (8) to suit the veterinary clinical setting. It can be easily adopted in all areas of clinical veterinary practice. The MCCG are used to break-down the management of the clinical case (consultation) into seven key components: 1. Preparation, 2. Initiating the Session, 3. Gathering Information, 4. Physical examination, 138
5. Explanation and Planning, 6. Closing the Consultation, 7. Providing Structure, and 8. Building the Relationship (5). The aim of this article which is designed to integrate clinical content with history gathering skills; thus, introducing the first three components of the model. Despite their equal importance, the skills associated with 'Explanation and Planning', 'Closing the Consultation', 'Building the Relationship' and 'Structuring the Consultation' which run after or in parallel to the discussed skills will not be the focus of this article.

Specifically, to help illustrate skills delineated in the MCCG, this article will focus on a fertility case of an individual cow ('Margery'). The specific information relating to this case is italicised. Some issues are not italicised as they are more general than specific and may be used in every day practice. The terminology used in this article has been adjusted to the typical language used in previous literature regarding the MCCG model. A consultation in this article encompasses the management of a clinical case, intervention, visit or a session. A client in this article refers to farm owner, manager, stockman, and/or attendant. A patient is the animal attended by the practitioner. The list of skills follows the originally developed by Kurtz et al. (5) for human practitioners with slight modifications to veterinary profession. The list of skills will be included as an appendix to the series or articles in the second part.

\section{PREPARATION}

Preparation for a bovine consultation involves the practitioner familiarising themselves with the past history of the client and, when applicable, the patient (Skill 0a) as well as anticipation of potential difficulties or conflicts regarding the client or the patient itself (Skill 0b).

\section{Establishing context}

Skill 0a (Familiarises with past history relating to client and animals(s)):

The modern veterinary practice will likely have a good filing system and appropriate computer software for management of clinical cases. Such systems should result in the rapid and easy retrieval of information. It is a good idea to familiarise with the previous history and clinical record of the farm, and if applicable of the patient to be examined.

E.g. The client (Mr Jack Bentley) is a regular client of your clinic, but you have never before been on his property or have met him. From the clinic records you have found that Mr Bentley has a mixed breed farm (Jersey, Holstein Friesian and 
Modified Calgary - Cambridge guides for consultations in bovine medicine

their crosses) of 120 cows that are well looked after, milking through 15 a-side herring bone milking parlour, mainly pastoral system with some supplemental feed when feed shortage occurs and some concentrate in the parlour. Each cow has her own name and identification number. Clinical records indicate that there are no obvious problems on the farm. Margery has not been seen previously for health problems at all.

Skill ob (Anticipates potential conflict of difficulties, relating to the client, the animal and to systems and infrastructures):

The filing system should also allow for adding special notes on the requirements of the client (e.g. client requires more time on explanations, client very knowledgeable of the subject) or the patient itself (e.g. may charge). It is important to approach the bovine consultation without pre-conceived ideas of their complexity or alternatively their simplicity.

\section{Creating a professional, safe and effective} environment

The creation of a professional, safe and effective environment should be tailored to the appropriate needs during the consultation (Skill 0c).

Skill Oc (Ensures facilities/environment are professional and appropriate to anticipated needs):

Independent of the previous relationship with the client, the practitioner should arrive on the farm presentable, in appropriate clothing and in a tidy vehicle. Professionalism of this type leaves a good impression. Furthermore, disinfecting working shoes upon arrival and departure is a biosecurity requirement. A spray bottle filled with ready-touse disinfectant is enough for this purpose. Finally, equipment should be clean and presentable (e.g. packed in a sterilisation pack, individually covered, and/or no residuals such as manure or saliva from the previous consultation).

For conducting a safe and complete clinical examination of the patient, appropriate facilities are required. It is the practitioner's duty to ensure that the working environment is safe and fit for purpose (e.g. operating crush, proper yards and raceway available). Old, damaged facilities may endanger the practitioner, the client or the patient.

E.g. the client has no crush for restraining Margery. The alternative is to use the dairy shed but the milking facilities are currently in use. This may require Margery to be examined on another occasion or in a portable crush brought in by the practitioner.

\section{Observation}

Skill Od (Continuous observation of the animal, the client and the environment):

The observation of the patient, the client and the environment should continue throughout the visit. The cattle patient cannot describe its symptoms. Hence, the observations of abnormalities (signs) made by the client are essential in forming a full picture about the case. The client should be observed for their competency in working with cattle, their attitude to handling cattle, honesty and the interest in the business as whole. E.g. an inexperienced client may be the reason for Margery not being seen in heat.

Furthermore, observation of the environment may provide clues for detecting risk factors that may have contributed to the incidence of the disorder. Unfortunately, the effects of the environment are often overlooked, and may not have received the consideration they deserve. The environment should be observed for the general state of the farm, location of the farm, topography, pasture, housing, walking surfaces, access to potentially dangerous goods and availability of feedstuffs and water, coupled with the cow comfort.

E.g. not having enough feedstuffs on the farm may indicate that malnutrition may be the reason for Margery not cycling (e.g. negative energy balance) or the slippery walking surfaces may prevent normal oestrous behaviour and heats may be missed.

Finally, practitioners should learn to ask only questions to which answers are not obvious. In some situations asking specific questions may be embarrassing (e.g. having been presented with a calving problem the sex of the patient should not be enquired). In these situations, the practitioners should take the obvious information as part of the history, without asking the questions.

\section{INITIATING THE SESSION}

Initiating the session encompasses the time from meeting the client, and sometimes the patient, until the reason for the visit is discussed.

\section{Establishing Initial Rapport}

An effective partnership is difficult to develop without first establishing initial rapport. Initial rapport is a first impression of the genuine and potential compatibility of a person and their capacity to work together. It characterised by establishing common ground through mutually objective topics. These topics might include the patient of interest 
or the weather in order to establish connection with the client and ability to connect mentally and emotionally with the other party; thus promoting trust and mutual respect (9).

Skills 1 (Greets the client; obtains/confirms client's name and the name/identity of the animal) \& 2 (Introduces self, role and nature of the consultation; obtains consent):

The initial few minutes of the consultation, particularly when meeting for the first time, will likely shape the relationship between the practitioner and the client, as well as the nature of future interactions. An introduction of the practitioner to the client (if they have not met previously) usually begins the consultation as well as the usual greetings of the day and the reason for the visit. Sometimes, it may be a good idea to indulge in a little general conversation before discussing the case. Conversation about the weather, a recent sporting event, and the recent introduction of an industry policy are the easiest and often most comfortable themes to discuss.

E.g. 'Good morning Mr Bentley (or Jack) ... My name is Dr John...' (shakes hands if the client is comfortable with this). 'How are you this morning? ...it has been cold the last few days, hasn't it? ... or 'I hope the price increase of the milk/meat last week is going to help the business ...'

This will likely help relax the atmosphere and the client does not feel like they are being interrogated and Skill 3 (Demonstrates interest, concern and respect for the client and the animal) demonstrates respect and interest in the client, the farm and the patient of interest.

By examining the body language of the client, the practitioner may be able to determine a suitable time to start the conversation about the case (Skill 3a. Attends to client's and animal's physical comfort). It is important to note that in an urgent clinical case (e.g. severe bleeding), it is still important to follow these guides. However, the practitioner after Skills 1 $\& 2$, will immediately deal with the case and while doing so inherently addresses the other aspects of developing initial rapport by meeting the client's needs.

\section{Identifying the reason for the consultation}

Following the development of initial rapport, it is important to ascertain the reason for the consultation. This is traditionally known as the client's concern/complaint.

Skill 4 (Identifies the client's problem or the issues that the client wishes to address):

The reason for the consultation is the concern expressed by the client. It must be clearly established 140 and verified with open-ended questions. Openended questions allow the client to provide as much information as they feel necessary and to explore their own concerns freely. e.g. 'What is the problem today?' or 'What can we do for you today?' or 'How can I help today?'

e.g. 'How can I help with Margery today?' or 'You mentioned over the phone that you have a cow with a problem. What is the problem that you have called for?' or 'You mentioned over the phone to the receptionist that Margery has a problem with not cycling. Can you clarify that for me?

The list of common complaints includes drooling from the mouth, swelling, lethargy, lameness, mastitis, distension of the abdomen, trouble breathing, diarrhoea, abnormal skin, abnormal milk, and dehydration. It is beyond the scope of this article to address all these in a single example. In our example the following reason for the consultation has been obtained:

'Margery has calved three months ago. I have not seen her in heat at all after calving. She is a high producer though.'

Therefore, the primary reason for the consultation in our case is that Margery is a non-cycling cow.

Skill 5 (Listens attentively to the client's opening statement, without interrupting or directing the client's response):

It is important that the practitioner listens attentively to the client's observations and response to questions, and actively determines as well as acknowledges the client's perspective. The skills associated with attentive listening are well described in Boudreau et al. (10). Amongst other features, attentive listening is an active and perceptual process and involves noticing nonverbal cues, verbal language and can assist in gathering diagnostic data. Attentive listening can be a difficult skill to consistently achieve and may be more difficult to learn than the clinical interview itself (10). Furthermore, a study of human medicine residents reported that patients are interrupted after an average of 12 seconds (11) and in a companion animal veterinarian study, clients were interrupted after just 11 seconds (12) thus suggesting attentive listening is indeed a challenging skill. An attentive listener should understand that the fact 'Margery is a high producer' mentioned at the start of the consultation means something to the client. This should stimulate further questioning, of an openended type, regarding the normal post-partum anoestrus interval of low versus high producing cows on the farm or the value of Margery for the client. If this questioning is omitted the client may feel disappointed that this was not completely understood. 
Modified Calgary - Cambridge guides for consultations in bovine medicine

Skill 6 (Checks and screens for further problems):

Finally, the client may have a range of concerns he/she wishes to raise. Dysart et al. (12) reported that open-ended questions designed to check for additional concerns resulted in veterinary clients expressing a fuller range of concerns. It is believed in human medicine literature that patients have multiple concerns and the first concern expressed is not always the most important (13). It is important to ascertain this at the outset, in order to efficiently structure the consultation and address all needs. Additionally, Dysart et al. (12) reported clients were four times more likely to voice late arising concerns when an initial solicitation for additional concerns was omitted. Furthermore, a study of physicians and their patients found that the way a solicitation of concerns is worded affects the likelihood that a patient will disclose their full range of concerns (14). The authors reported that the question "Is there something else you want to address today" resulted in a reduction of patient unmet concerns rather than 'Is there anything else you to want to address in the visit today' or a variant 'Do you have any questions?' A more effective solicitation would be. 'So you've noticed a drop in milk production ... Is there something else?'

E.g. 'So you have noticed that Margery is not coming in heat. Did you have something else you wanted to raise with me today?'

The loop of asking for any additional concerns from the client can be repeated until he/she says that everything seems to be addressed (e.g. 'I think that's all').

Skill 7 (Negotiates agenda taking both the client's and practitioner's needs into account):

When there are multiple problems in the same patient, the practitioner should negotiate the order of addressing problems using a logical explanation for the agenda. Effective solicitation of needs is likely to allow for effective time allocation in the consultation and does not lead to longer consultations $(14,15)$ as well as reducing late arising concerns (15). During negotiation of the order of addressing concerns, the practitioner should take into account multiple factors including the needs of the client, ensuring efficiency with the agenda, acknowledging the physical or time constraints of the practitioner or the facility, as well as biosecurity requirements.

E.g. 'So, we'll look at the infected hoof first and then we'll talk about the milk yield ... is that okay?' It is most likely that the client will wish to prioritise the chief clinical concern, rather than other aspects the practitioner deems equally important. There are two agendas in every consultation; the practitioner and the clients. An aspect of the art of communication is being able to meet both needs in a relatively short time frame.

E.g. 'We will discuss Margery's problem in detail and then we will talk about the farm and the herd. Does this sound reasonable?' or 'So, we will look at problem with the fertility first and then we will check the leg. I think this is better to prevent contamination to the reproductive organs with bugs from the foot....pause...is that okay?'

\section{GATHERING INFORMATION}

Gathering information includes four important steps in case management namely 1) gathering a history, 2) clinical examination, 3) ancillary examination techniques and 4) collecting and assaying appropriate samples. Addressing all four steps in gathering information is not within the scope of this article; gathering a history is the focus. For the other three steps in gathering information (clinical examination, ancillary examination techniques and collection and assaying appropriate samples) readers are referred to numerous textbooks and reviews on clinical examination of cattle examples.

\section{Gathering a history}

Gathering a precise, complete and relevant history is a key step to an accurate diagnosis and in fact contributes $60-80 \%$ of the data for diagnosis in human medicine (16). The clinical content of gathering history, particularly for a non-experienced practitioner, may be aided by examination checklists allowing for consistency in obtaining initial information. In general, there are two types of histories; the complete and the focussed history (16). A complete history is usually gathered for a first consultation and includes the client's problem list, the clinical (patient and disorder) data, the client's perspective and background information including general history (Table 1). A more focussed interview is often used for follow-up appointments and is the same as the complete history, but includes only selective discussion of pertinent background information. It is important to ensure that during each consultation, regardless of time between visits, those changes to management practice are routinely sought. 
Petrovski K. and McArthur M.

Table 1. Elements of gathering history

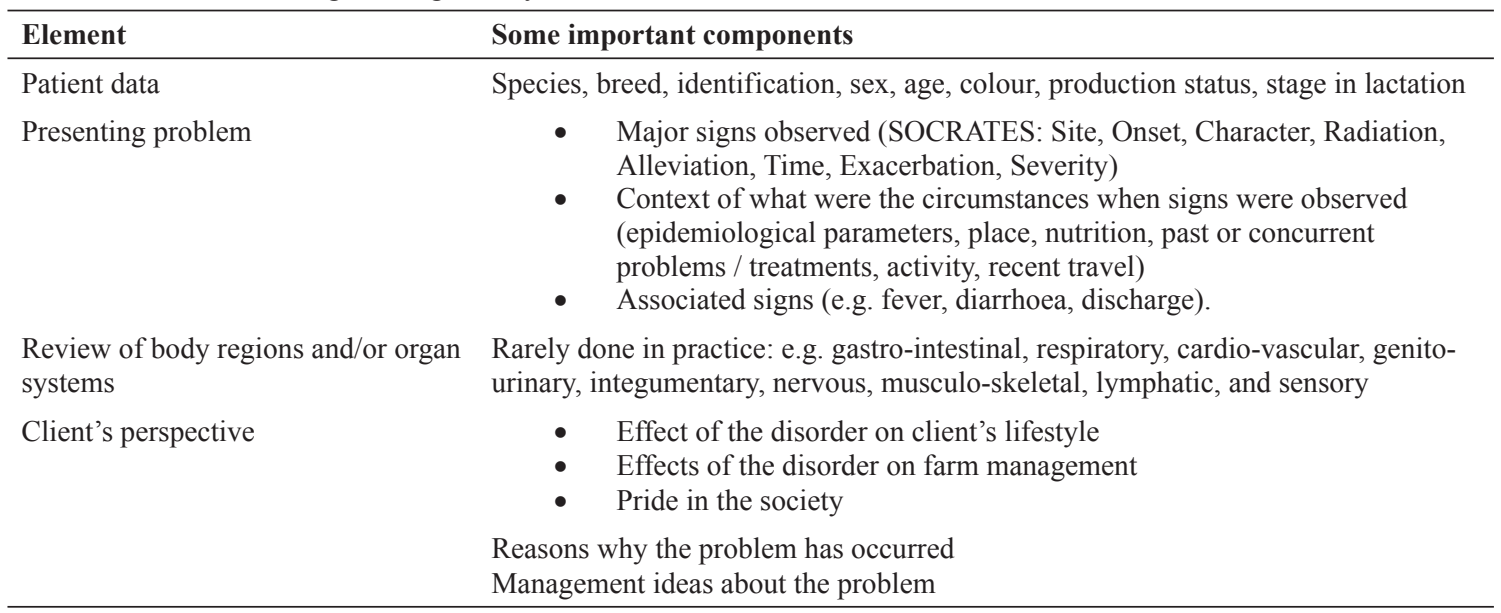

The accuracy of information provided by clients may be variable due to a number of factors, many of which are inherent to the professional nature of the farming client. It is important to remember that the client is an expert in his/her own right. The client has expertise in the farm and its management, characteristics of their stock and their own capacity for management. An aspect of this expertise may be elucidated through careful and accurate observations which clients make when describing clinical concerns. History obtained from such a client may be of great assistance in establishing the diagnosis. Other clients may be less observant or not experienced enough to detect the abnormalities. Therefore, history obtained from such a client may have some level of inaccuracy and relies upon the expertise of the practitioner in deciphering this. Some inaccuracy may reflect how closely cattle are being monitored (i.e. beef vs. dairy cattle, dry vs. milking cows). On very rare occasions, the answers to the questions may be deliberately untrue in an attempt to cover incompetency, fraudulent action or negligence. The accuracy of the answers has to be carefully assessed during the examination process. Consequently, it is vital that a collaborative relationship is established to enable both parties to work together in collecting an accurate history.

\section{Exploration of client's problems}

Skill 8 (Encourages client to tell the story of the animal's problem/s from when it first started to the present in their own words):

The practitioner should encourage the client to tell the story in the client's own words and guide the client towards the necessary detail, clarity and completeness for diagnostic accuracy (17). Often, a client will come with a pre-prepared narrative of the concerns and it requires patience on the part of the veterinarian to listen to the full account. The payoff is considerable. Hearing the client's full narrative gives the practitioner insight into how the client is understanding and interpreting events and at what level. Additionally, the client may provide detail that the practitioner may have overlooked (17).

E.g. 'Can you walk me through what you have seen with Margery from calving to now?' or 'You told me that Margery has not cycled since calving. Can you tell me how her calving was?"

Skill 9 (Uses open and closed questions, appropriately moving from open to closed):

A 'cone' or 'funnel' approach to question asking is suggested as most efficacious in the clinical interview. Questioning about the history should progress from open-ended (e.g. How's her appetite?' or 'Can you tell me how was Margery's calving?') to more narrow open-ended questions 'Can you describe the force that you used to pulled her calf?' to closed-ended questions (e.g. 'How many times was she sick' or 'How often per do day you check if Margery is in heat?'). Open-ended questions permit the client to tell his/her story in their own words, from their own perspective, and to give the client space to ensure his/hers agenda is met. The effective use of open-ended questions in veterinary medicine is believed to increase client adherence and satisfaction as well as prevent premature hypothesis generation (18). Interestingly, open-ended questions were used in $10 / 65(15 \%)$ of companion animal veterinary consultations, thus veterinarians relied on a series of closed-ended questions to gather a complete history from their client (19). Closed-ended questions serve an important purpose in clarifying details, ensuring completeness of the history and ultimately ensuring the practitioner's agenda is covered. It is of interest to note the difference between open- and closedended questions as outlined in Table 2; in so much as every closed-ended question can easily become an open-ended question. 
Modified Calgary - Cambridge guides for consultations in bovine medicine

Table 2. Examples of open- and closed - ended questions for gathering information

\begin{tabular}{ll}
\hline Open-ended questions & Closed-ended questions \\
\hline Tell me about Margery's walking. & How long has Margery been walking awkwardly? \\
Describe to me what you have seen. & Did you notice if she was able to walk in a straight line? \\
What has Margery been offered in the feed bunk? & Does Margery have easy access to the feed bunk? \\
How is Margery acting in the presence of humans? & Does Margery run away from you? \\
How do you feel about this outcome? & Are you happy with this outcome? \\
\hline
\end{tabular}

It is imperative that the questioning is nonjudgmental (e.g. 'Are you sure you have not missed her being in heat?') and without the use of leading questions (e.g. 'Margery's calving was OK, wasn't it?'). Anecdotally, it is often suggested that closedended questions can save time. However, used in isolation they often produce misleading or inaccurate answers and may require a return to the same issue later in the consultation; thus suggesting a false economy. In fact, open-ended questions are part of a cluster of skills inherent to relationship-centred styles of communication which are associated with increased patient satisfaction and similar, if not reduced, consultation length (20).Enquiry type and tact are particularly important for the chronology of the disorder, as many clients may feel responsible for not taking action when the first abnormalities were observed and, therefore, may try to cover their oversight or neglect.

Skill 10 (Listens attentively, allowing the client to complete statements without interruptions and leaving time for the client to think before answering):

To be effective at gathering information, practitioners must learn to get the right balance between listening and questioning. This is an important aspect of the practitioner's 'bedside manner' and is essential if the appropriate information is to be gathered. The client should be allowed to finish their statement without interruption. Another related problem occurs when there is too much unstructured questioning which can come across as an interrogation. Once interrupted with sub-questions or paraphrasing of the first expressed problem, the client may not feel confident introducing new issues (21).

\section{Skill 11 (Facilitates the client responses verbally and non-verbally):}

It is important to encourage the client to complete their response. There are several ways to achieve this goal including encouragement and silence (16). The first, encouragement, is in the form of verbal utterances "Yes... (pause)... go on", "Uh huh" or nonverbally by head nodding and other facial and nonverbal indicators expressing interest. Second, silence or a momentary pause often gives enough space for the client to finish their thought. Interestingly, when teachers were trained to pause for three seconds at key times following question asking, students were more inclined to ask questions, spoke for longer duration and even those quieter students contributed. Similar effect has been reported in human medicine and is expected to be valid for clients presenting cattle problems.

Skill 12 (Picks up verbal and non-verbal cues from the client, checks out and acknowledges as appropriate):

Clients will use nonverbal methods to communicate the message a staggering $80 \%$ of the time and actual verbal utterances account for the remaining $20 \%$ or sometimes less (22). Accordingly, the practitioner will need to attend to both the verbal message and nonverbal cues expressed by the client. Noticing the cue is the first step, responding and acknowledging it, the second. This can be achieved by stating, where the practitioner notices a look of discomfort in the form of facial expressions or hand movements "Am I right in thinking you have been unhappy with the treatment provided in the past?" or noticing the cue, can be as simple as repeating the cue expressed by the client, for example "Wished you had called earlier...?" "Financially stressed...?" Interestingly, acknowledging the patient's cues has been found to shorten consultations (22), quite possibly due to patients not needing to raise the same issues repeatedly in an attempt to be understood or worse, giving up.

"You seem to be concerned about the results I have given you. Would you like to discuss this now or do you want to have a think first and we can discuss this at the next visit?"

\section{Skill 13 (Clarifies statements that are vague or} need amplification):

Clients may provide responses which are vague and will require prompts for clarity, detail or completeness from the practitioner. Additionally, the way each person perceives an experience is likely different from another. For example a client 
responds, in the case of Margery, with " $a$ lot of discharge from the vagina" the definition of "a lot" and for that matter "discharge" may be different from that of the practitioner. Consequently clarifying questions such as "Could you please describe what you mean by a lot of vaginal discharge?" are invaluable for accuracy.

Skill 14 (Periodically summarises to verify own understanding of what the client has said):

It is advisable that the practitioner overtly repeats the verbal information provided by the client. Repetition demonstrates understanding of the information obtained from the client, allows the client time to confirm or change the meaning and ensures accuracy (16). Specifically, two skills are of interest; paraphrasing and summarising. A paraphrase involves using the practitioner's own words to clarify or encourage the client to continue e.g. "So you've had a difficult time lately with Margery...". A summary can represent an internal summary or a summary designed to be used at various times throughout the gathering information phase (16). It should include both the client's perspective as well as the clinical information obtained. (e.g. "You have noticed that Margery had some discharge from the vagina for about a week that began approximately two weeks after calving and you thought it might have been related to her decreased appetite... (pause) ... is there something else? While summaries are a vital aspect of information gathering, when repeatedly inaccurate, clients may experience the physician as being inattentive and not understanding their concerns (23).

Skill 15 (Uses concise, easily understood language, avoiding or adequately explaining jargon):

The use of non-technical terms during the gathering history phase helps to ensure the client understands questions being asked of them. For example, the client will easily understand in heat, but may be unfamiliar with the term oestrus. Interestingly, an North American report written in 2005 reported the majority of adults read at an $8^{\text {th }}$ grade level but most health information is written at a year 10 reading level (24). Moreover, a study of medical residents found that they significantly overestimated the health literacy of their patients and erroneously made judgements of their patients' capacity for understanding based on their completed year of high school (25). Taken together, these results strongly advocate the use of client-friendly language.
Additional skills for understanding client's perspective

The client's perspective incorporates the beliefs, ideas, concerns, role of the individual patient/herd on the farm, expectations and how the problem affects client's life as well as the management of the enterprise. An appreciation and incorporation of the client's perspective is fundamental to the development of a collaborative approach. Numerous positive outcomes have been realised with human medicine clinicians employing a relationshipcentred style of communication including patient satisfaction (26), loyalty and commitment to the individual practitioner, as well as enhanced adherence to treatment and recommendations (27). Similar benefits are expected for veterinarians.

\section{Skills 16a (Determines and acknowledges client's ideas and concerns regarding each problem):}

The client may request a bovine consultation with a preconceived notion or diagnosis of the presenting problem. The client's formulation may or may not be accurate. However, in formulating this diagnosis, for example "Margery having inactive ovaries", the client may have ideas about how to treat the inactivity, what the effect will be and concerns related to its management. It is important that the practitioner determines these ideas and concerns early in the consultation and importantly, acknowledges them with questions such as:

"What do you think is the cause?", "Have you got any ideas about what is happening here?" and/ or "Is there something that particularly concerns you?"

The client responds: 'Margery is not cycling. She is certainly looking the same as Mooie who had inactive ovaries.' At this point the practitioner is well aware of the client's formulation and is better equipped to manage the client's expectations of diagnosis and treatment based on this formulation. Without this information, discussion of the diagnosis and treatment plan may be met with resistance as the client may be confused or shocked by the information provided by the practitioner. This can negatively affect adherence and the ongoing collaborative relationship.

\section{Skill $16 \mathrm{~b}$ (Determines and acknowledges} client's expectations):

The client will have expectations about the care provided by the practitioner, the outcomes and perhaps the process for the consultation. It is useful to determine these expectations with questions such as "It seems you have thought a lot about this. What 
Modified Calgary - Cambridge guides for consultations in bovine medicine

were you thinking is the best course of action?" or "What were you hoping for today?"

E.g. "OK, Jack. Seems you have thought a lot about Margery's problem and researched this issue on the internet. She does share some similar symptoms to Mooie. However, Margery has active ovaries and probably is cycling regularly but has not been detected. It is very likely she is a high producer to have so-called 'silent heats'. We can leave it to run its course hoping you will detect her at the next cycle or we can use hormonal treatment to use fixed time artificial insemination. What would be the preferred option for Margery today?"

\section{Skill 16c (Determines and acknowledges how each problem affects the client):}

Finally, it is essential that the practitioner determines how each noted problem impacts the management of the enterprise and life of the client. For example, "I get the sense that you want to change your heat detection, and you have concerns about your production and lifestyle. Please, let me know how this affects you." A question of this type provides an excellent entry point to understanding the client's perspective and helps to plan treatment within the capacity of the client with minimal changes to the management of the cattle enterprise. Ultimately, understanding this information should enhance adherence to treatment and the recommended course of action as it is specifically tailored to the needs of that particular client.

In our example of Margery being one of the cows characterised with a 'silent heat' the client is interested in how to recognise these cows. With the second explanation, the client is interested immediately how to recognise these cows. The practitioner could explain that the use of more 'in heat' observations per day or oestrus detection aids may assist is a logical continuation of the discussion.

Skill 17 (Encourages expression of the client's feelings and thoughts):

In determining the client's perspective, it is important for the practitioner to allow the client to express the thoughts and feelings with regard to the information provided and decisions made. These issues will also need to be addressed as required.

"Jack, I think you have read a lot about noncycling cows. Do you agree with what we have discussed? Tell me what you think about it."

\section{CONCLUSIONS}

Appropriate communication skills are essential to successful companion and production animal veterinary practice, including practitioners. The
MCCG as exemplified above, provides a useful framework for integrating clinical communication skills with clinical content; a must for effective consultations. The MCCG are relevant to all veterinary practitioners from production to equine to companion animal veterinarians. Communication both verbal and non-verbal is a cornerstone skill in building a relationship with the client and directly influences the outcome of the consultation, treatment and adherence to recommendations $(18,28)$.

\section{ACKNOWLEDGMENTS}

KRP was responsible for the idea, preliminary write up and clinical aspects of the article. MMM was responsible for the theoretical basis and contributed to the writing and editing of the manuscript.

\section{REFERENCES}

1. Kanji, N., J. B. Coe, Adams, C. L., Shaw J. R. (2012). Effect of veterinarian-client-patient interactions on client adherence to dentistry and surgery recommendations in companion-animal practice. J Am Vet Med Assoc. 240(4): 427-436. http://dx.doi.org/10.2460/javma.240.4.427 PMid:22309015

2. Coe, J.B., Adams, C.L. Bonnett, B.N. (2008). A focus group study of veterinarians' and pet owners' perceptions of veterinarian-client communication in companion animal practice. Journal of the American Veterinary Medical Association 233(7): 1072-1080. http://dx.doi.org/10.2460/javma.233.7.1072 PMid:18828715

3. Shaw, J.R., Adams, C. L., Bonnett, B.N., Larson, S., Roter, D.L (2012). Veterinarian satisfaction with companion animal visits. Journal of the American Veterinary Medical Association 240(7): 832-41. http://dx.doi.org/10.2460/javma.240.7.832 PMid:22443436

4. Sandler, G. (1979). Costs of unnecessary tests. British Medical Journal. 7(2): p. 21-4.

http://dx.doi.org/10.1136/bmj.2.6181.21

5. Kurtz, S., Silverman, J., Benson, J., Draper, J. (2003). Marrying content and process in clinical method teaching: Enhancing the Calgary-Cambridge guides. Academic Medicine. 78 (8): 802-809. http://dx.doi.org/10.1097/00001888-200308000-00011 PMid:12915371

6. Gillard, S., Benson, J., Silverman, J. (2009). Teaching and assessment of explanation and planning in medical schools in the United Kingdom: cross sectional questionnaire survey. Med Teach. 31 (4): 328-331. http://dx.doi.org/10.1080/01421590801953018 PMid:19142799 
7. Adams, C.L., Kurtz, S.M. (2006). Building on existing models from human medical education to develop a communication curriculum in veterinary medicine. $\mathrm{J}$ Vet Med Educ. 33 (1): 28-37.

http://dx.doi.org/10.3138/jvme.33.1.28 PMid:16767635

8. Radford, A., Stockley, P., Silverman, J., Taylor, I., Turner, R., Gray, C. (2006). Development, teaching, and evaluation of a consultation structure model for use in veterinary education. J Vet Med Educ. 33(1): $38-44$.

http://dx.doi.org/10.3138/jvme.33.1.38

PMid:16767636

9. Moulton, L. (2007). The naked consultation: A practical guide to primary consultation skills. Abingdon, UK: Radcliffe.

10. Boudreau, J.D., Cassell, E. Fuks, A. (2009). Preparing medical students to become attentive listeners. Med Teach. 31 (1): 22-29.

http://dx.doi.org/10.1080/01421590802350776

PMid:19140065

11. Rhoades, D.R., McFarland, K.F. Finch, W.H., Johnson, A.O. (2001). Speaking and interruptions during primary care office visits. Fam Med. 33 (7): 528-532.

PMid:11456245

12. Dysart, L.M., Coe, J.B., Adams, C.L. (2011). Analysis of solicitation of client concerns in companion animal practice. Journal of the American Veterinary Medical Association. 238 (12): 1609-1615.

http://dx.doi.org/10.2460/javma.238.12.1609

PMid:21671816

13. Beckman, H., Frankel, R. (1984). The effect of physician behaviour on the collection of data. Annals of Internal Medicine. 9 (9): 517-521.

14. Heritage, J., Robinson, J. D., Elliott, M. N., Beckett,M., Wilkes, M. (2007). Reducing patients' unmet concerns in primary care: the difference one word can make. Journal of General Internal Medicine. 22 (10): 1429-33. http://dx.doi.org/10.1007/s11606-007-0279-0 PMid:17674111 PMCid:PMC2305862

15. Brock, D.M., Mauksch, L. B., Witteborn, S., Hummel, J., Nagasawa, P., Robins, L.S. (2011). Effectiveness of intensive physician training in upfront agenda setting. Journal of General Internal Medicine. 26 (11): 1317-1323.

http://dx.doi.org/10.1007/s11606-011-1773-y PMid:21735348 PMCid:PMC3208461

16. Silverman, J.D., Kurtz, S., Draper, J. (2005). Skills for communicating with patients. $2^{\text {nd }}$ ed. Oxford: Radcliffe Publishing.

146
17. Lipkin, M., Putnam, S.M., Lazare, A. eds (1995). The Medical Interview: Clinical Care Education and Research. Springer-Verlag: New York. http://dx.doi.org/10.1007/978-1-4612-2488-4

18. Shaw, J. (2006). Four core communication skills of highly effective practitioners. Veterinary Clinics of NorthAmerica-SmallAnimalPractice.36(2):385-396. http://dx.doi.org/10.1016/j.cvsm.2005.10.009 PMid:16442449

19. McArthur, M. Fitzgerald, J. (2013). Companion animal veterinarians' use of clinical communication skills. Aust Vet J. 91 (9): 374-380.

http://dx.doi.org/10.1111/avj.12083

PMid:23980830

20. Abdel-Tawab, N. Roter, D. (2002). The relevance of client-centred communication to family planning settings in developing countries: lessons from the Egyptian experience. Social Science and Medicine. 54, 1357-1368. http://dx.doi.org/10.1016/S0277-9536(01)00101-0

21. Gask, L., Usherwood, T. (2002). ABC of psychological medicine. The consultation. BMJ. 324 (7353): 1567-1569.

http://dx.doi.org/10.1136/bmj.324.7353.1567

PMid:12089097 PMCid:PMC1123505

22. Levinson, W., Gorawara-Bhat, R., Lamb, J. (2000). A study of patient clues and physician responses in primary care and surgical settings. Journal of the American Medical Association 284, 1021-1027. http://dx.doi.org/10.1001/jama.284.8.1021 PMid:10944650

23. Quilligan, S., Silverman, J. (2012). The skill of summary in clinician-patient communication: a case study. Patient Educ Couns. 86 (3): 354-359. http://dx.doi.org/10.1016/j.pec.2011.07.009 PMid:21821377

24. Safeer, R.S., Keenan, J. (2005). Health literacy: the gap between physicians and patients. Am Fam Physician. 72 (3): 463-468.

PMid:16100861

25. Bass, P.F., Wilson, J. F., Griffith, C. H., Barnett, D. R. (2002). Residents' ability to identify patients with poor literacy skills. Acad Med. 77 (10): 1039-1041. http://dx.doi.org/10.1097/00001888-200210000-00021 PMid:12377684

26. McMillan, S.S., Kendall, E., Sav, A., King, M. A., Whitty, J. A., Kelly, F., Wheeler, A. J. (2013). Patientcentered approaches to health care: a systematic review of randomized controlled trials. Med Care Res Rev. 70 (6): 567-596. http://dx.doi.org/10.1177/1077558713496318 PMid:23894060 
27. Robinson, J.H., et al. (2008). Patient-centered care and adherence: definitions and applications to improve outcomes. J Am Acad Nurse Pract. 20 (12): 600-607. http://dx.doi.org/10.1111/j.1745-7599.2008.00360.x PMid:19120591
28. Kleen, J.L., Atkinson, O., Noordhuizen, J. (2011). Communication in production animal medicine: modelling a complex interaction with the example of dairy herd health medicine. Irish Veterinary Journal. 64. http://dx.doi.org/10.1186/2046-0481-64-8

PMid:21777495 PMCid:PMC3156738 